\title{
The dual-fuel CFD combustion model with direct and indirect CNG injection
}

\author{
Tytus Tulwin ${ }^{1, *}$, and Rafat Sochaczewski ${ }^{2}$ \\ ${ }^{1}$ Lublin University of Technology, Mechanical Engineering Faculty, ul. Nadbystrzycka 36, 20-618 Lublin, Poland \\ ${ }^{2}$ Pope John Paul II State School of Higher Education, Department of Mechanical Engineering, ul. Sidorska 95/97, 21-500 Biala Podlaska, \\ Poland
}

\begin{abstract}
A proper design of the compression ignition engine fuel system requires various fuel injection methods analysis. Direct and indirect CNG injection process simulation research was conducted. The results allow a mixture homogeneity analysis and its impact on combustion process and heat transfer. For an indirect injection the injector is placed in intake channel and the injection is performed during an intake stroke. For a direct injection the specially designed injector is installed in the glow plug position. The analysed case is set for $20 \%$ energetic ratio of diesel fuel and $80 \%$ of methane fuel. In order to perform the calculations a special combustion model has been implemented that allows duel-fuel combustion in a compression ignition engine.
\end{abstract}

\section{Introduction}

CNG gas is well suited as an additive fuel to a compression ignition engine. Methane autoignition occurs at the temperature of $537^{\circ} \mathrm{C}$, decreasing the chance of premature ignition during the compression stroke. Additionally, methane has good anti-knock combustion properties with equivalent octane number of 120 . CNG is relatively ecological when compared to the gasoline or diesel, because the reaction produces mainly water and carbon dioxide. There aren't many additives to this fuel so there are fewer toxic products. The main problems of $\mathrm{CNG}$ fuel are storage and transport. The CNG fuel requires high pressures above $20 \mathrm{MPa}$, what requires appropriate installation. Table 1 presents the comparison of different combustion engine fuels [1].

Table 1. CNG, gasoline and diesel properties comparison.

\begin{tabular}{|c|c|c|c|}
\hline $\begin{array}{c}\text { Lower heating } \\
\text { value } \\
\mathrm{MJ} / \mathrm{kg}\end{array}$ & 48.5 & 42.5 & 41.7 \\
\hline $\begin{array}{c}\text { Higher heating } \\
\text { value } \\
\mathrm{MJ} / \mathrm{kg}\end{array}$ & 53.9 & 46.7 & 44.8 \\
\hline $\begin{array}{c}\text { Autoignition } \\
\text { temperature }\end{array}{ }^{\circ} \mathrm{C}$ & $\begin{array}{c}630- \\
640\end{array}$ & $320-360$ & $550-600$ \\
\hline $\begin{array}{c}\text { Octane number } \\
115-\end{array}$ & $90-98$ & 25 \\
\hline Density kg/m3 & 0.73 & $700-750$ & 800 \\
\hline $\begin{array}{c}\text { Air-fuel ratio } \\
\mathrm{kg} / \mathrm{kg}\end{array}$ & 17.2 & 14.8 & 14.3 \\
\hline
\end{tabular}

An internal combustion engine with high pressure direct fuel injection can be described with high thermodynamic efficiency thanks to stratified lean mixture combustion. Air excess that doesn't participate in combustion help to isolate the hot combustion gases from engine walls, therefore increasing efficiency. Additionally, the $\mathrm{CO}, \mathrm{CO} 2$ and $\mathrm{HC}$ emissions are lower. In the following research the $\mathrm{CNG}$ injection is analysed for two cases: direct and indirect injection method. The direct injection method is characterised by the specially designed injector located in the combustion chamber, in the place of the glow plug. The indirect injection method is characterised by the injector located in the intake manifold wall outside the combustion chamber, as a multi-point injection. Both methods increase the homogeneity of the fuel-air mixture prior to the combustion - this effect is analysed in this paper [2].

\section{Materials and methods}

Accuracy of the simulation results of the simulation model is proved on the basis of the actual engine pressure at the same operating point - at partial load of $170 \mathrm{Nm}$ and rotational speed of $n=3200 \mathrm{rpm}$. It is often difficult to take measurements inside the combustion engines, because of limited confined space. Often, required data must be indirectly approximated. A lot of combustion information can be obtained from the pressure readings. For the verification of the combustion model the heat generation rate was analysed. Its value as a function of time is derived from equation 1.

$$
\frac{d Q_{n}}{d t}=\frac{\gamma}{\gamma-1} \cdot p \cdot \frac{d V}{d t}+\frac{1}{\gamma-1} \cdot V \cdot \frac{d p}{d t}
$$

\footnotetext{
* Corresponding author: t.tulwin@pollub.pl

(C) The Authors, published by EDP Sciences. This is an open access article distributed under the terms of the Creative Commons Attribution 
where: dQn - amount of heat change, $\gamma$ - adiabatic index for chamber mixture, $\mathrm{p}$ - instantaneous mean cylinder pressure and $\mathrm{V}$ - instantaneous combustion chamber volume. The value of $\mathrm{dQn} / \mathrm{dt}$ is expressed in $\mathrm{J} / \mathrm{s}$. The adiabatic index of gases in the combustion chamber is unknown in this equation. It is mainly temperature dependent, so no large error has been made assuming its constant value in the typical range of its occurrence (between 1.3 and 1.4). By combining the heat generation rate (equation 1 ), the heat generated during the combustion process was obtained without taking into account the heat loss via cooling:

$$
Q=\int_{t_{1}}^{t_{2}} \frac{d Q}{d t} d t=m_{f} \cdot W_{t}
$$

where: $\mathrm{Q}$-overall heat dissipated, $\mathrm{mf}$ - fuel mass, $\mathrm{Wt}$ lower heating value and $t_{1}, t_{2}-$ combustion process integral time limits. Figure 1 shows the heat generation rate in respect to the crankshaft position, for the actual and computed case. Values for both cases were calculated using equation 1 based on the actual cylinder pressure and simulated cylinder pressure. The verification case considers a full dose of diesel fuel injection without $\mathrm{CNG}$ injection.

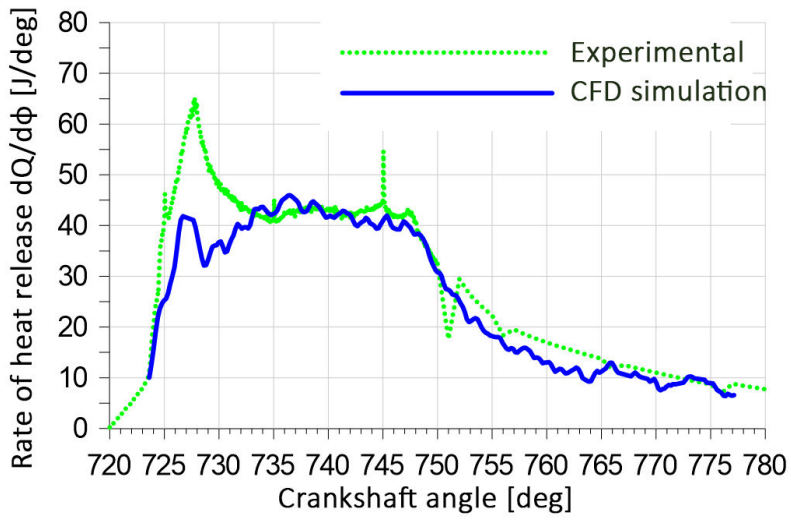

Fig. 1 Rate of heat release for experimental and CFD simulation results.

As shown in figure 1, both curves are closely aligned in the middle and at the end of the injection phase $\left(>735{ }^{\circ} \mathrm{CA}\right)$. This is the period of the diffusion combustion. The evaporation rate reaches plateau, causing a constant rate of heat release up to $748{ }^{\circ} \mathrm{CA}$, where the injector closes. Fuel residues burn up for a longer time in relation to the injection time. An exemplary fuel injection flame visualisation is shown in figure 2. During the initial injection phase $\left(<735{ }^{\circ} \mathrm{CA}\right)$ the fuel atomizes already in the injector nozzle, increasingly as penetration through the dense air in the combustion chamber. At first, the fuel mixture too rich to ignite. When the air is mixed sufficiently with the fuel there is a rapid combustion burst characterized by a peak in the rate of heat release graph. Figure 1 shows a small difference between real and computational cases, due to insufficient refinement of the computational mesh at the injection site, which is justified by the limitation of the calculation time of the workstation. However, for comparative purposes, the injection phase has been sufficiently reflected [3].

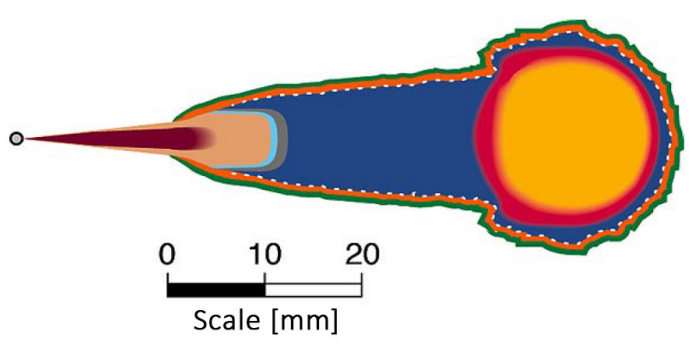

Fig. 2 Developed fuel injection for a typical diesel engine.

Information about the injector diameter and injection pressure allows to calculate the injection angle. High in-cylinder pressures empirical coefficients were assumed based on the results of the study. The injection stream angle was determined basing on equation 3 :

$$
\propto=2 \cdot \tan ^{-1}\left(0,00751 \cdot W_{e}^{0,32} \cdot M^{-0,07} \cdot \delta^{0,5}\right)
$$

where $\delta$ is the ratio of mixture density to the fuel density. The Mach number is represented by the equation:

$$
M=\frac{\mu^{2}}{\rho \cdot d \cdot \sigma}
$$

where: $\mathrm{d}$ is the injector nozzle diameter, $\sigma$ is the surface tension, $\mu$ is the dynamic viscosity of the fuel. We is a Weber number, represented by the equation:

$$
W_{e}=\frac{\rho \cdot w^{2} \cdot d}{\sigma}
$$

The fuel stream velocity can be calculated by using Bernoulli equation for incompressible fluids:

$$
w=\sqrt{2 \cdot \frac{\Delta p}{\rho}}
$$

where $\Delta \mathrm{p}$ is an injector pressure difference and $\rho$ is a fuel density. Based on the maximum stream flow velocity an adequate injector mass-flow was formulated [4][5][6].

\section{Results and discussion}

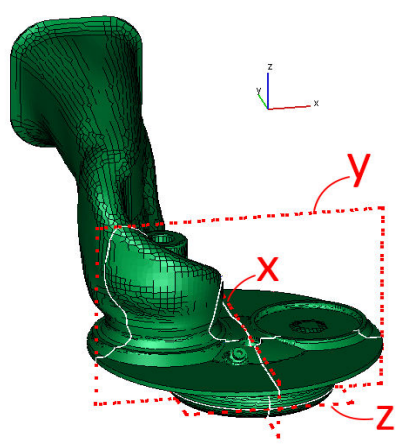

Fig. 3 Computational grid for CFD simulation model. 
Figure 3 shows the ADCR diesel engine computational mesh. Reference planes for later visualisations are indicated. Two methods of supplying the $\mathrm{CNG}$ gas have been tested: indirect gas injection into the intake manifold and direct injection of gas into the combustion chamber. Figure 1 shows the locations of the injectors. Figure 4 shows the effect of the gasoline engine feed method on the decomposition of the mixture just before ignition $\left(720^{\circ} \mathrm{CA}\right)$. Indirect gas injection causes a homogeneous mixture formation. A long mixing path and time resulted in a uniform $\mathrm{CH} 4$ distribution in the combustion chamber. Direct injection of methane results in uneven distribution of methane. At the bottom of the combustion chamber, the $\mathrm{CH} 4$ concentration is only $1 \%$, when the uppermost part of the chamber is filled with a mixture containing up to $4 \%$ methane. The main advantage of direct injection is the fact that the entire fuel dose goes directly into the combustion chamber and takes part in combustion process during the same cycle. Indirect injection does not guarantee that the entire injected dose will reach the combustion chamber during the same cycle. This is important in states of transient engine operation.

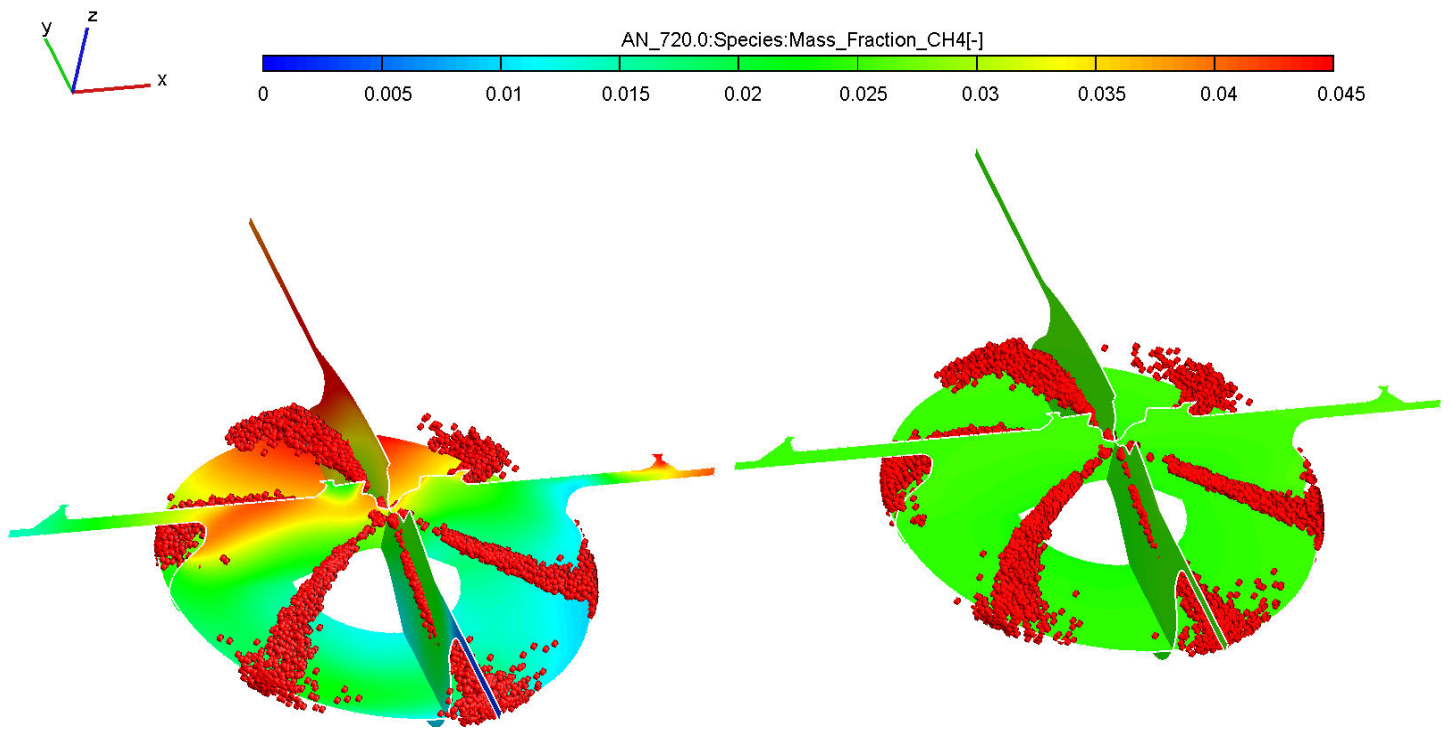

Fig. 4 Methane mass fraction and diesel droplets in case of direct and indirect gas injection.

The influence of the injection method on the cylinder pressure is shown in Figure 5. The direct injection occurs after the intake valve closes, increasing the mass of the mixture in the cylinder. This translates into increased maximal compression pressure (up to $0.4 \mathrm{MPa}$ ).

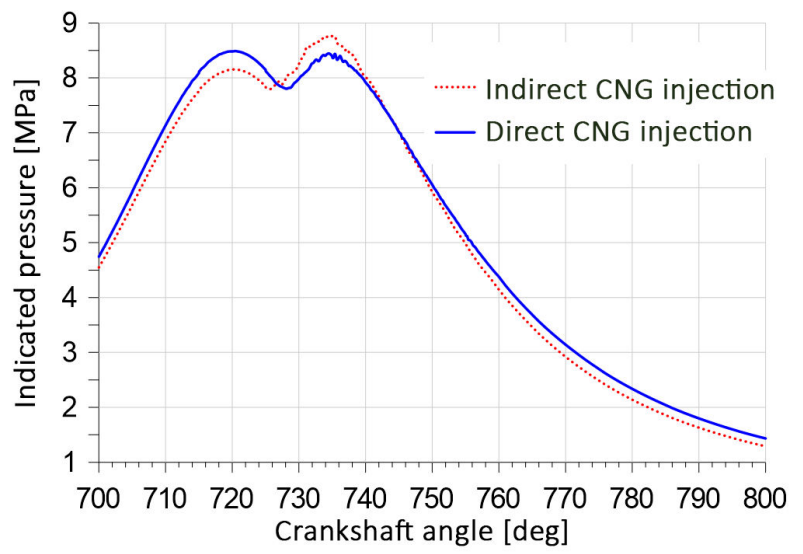

Fig. 5 Cylinder pressure for direct and indirect injection case.

Despite increased pressure, the ignition occurs later. In the case of indirect injection methane and air mixture is homogeneous. Ignition of the initial injection phase is accelerated. Pressure has significant influence on the beginning of self-ignition through chemical, physical phenomena and the local composition of the combustion mixture. It is difficult to predict the unambiguous influence when the abovementioned phenomena are nonlinear. Local enrichment of the combustion mixture results in a reduction of the self-ignition delay. Increasing pressure (at pressures $>$ $7 \mathrm{MPa}$ ) increases the delay caused by chemical effects by decreasing the diffusion coefficient. However, the impact on the delay is influenced by the injection phenomena. These include: reduced jet penetration, reduced droplet evaporation and lower fuel flow rates through the injector. Figure 6 shows the locations of auto-ignition sources for both injection cases. Comparing the distribution of the CNG blend (Fig. 4), it is possible to see the premature ignition of the mixture in the fuel-rich areas of the combustion chamber compared to the rest of the mixture. This causes an uneven fuel ignition throughout the combustion chamber. Nevertheless, combustion is more stratified due to better insulation of the cylinder walls and a longer diffusion period. The advantage of CNG injection, by forming a homogeneous mixture, is the reduction of soot formation which occurs in poor combustion areas [7][8]. 


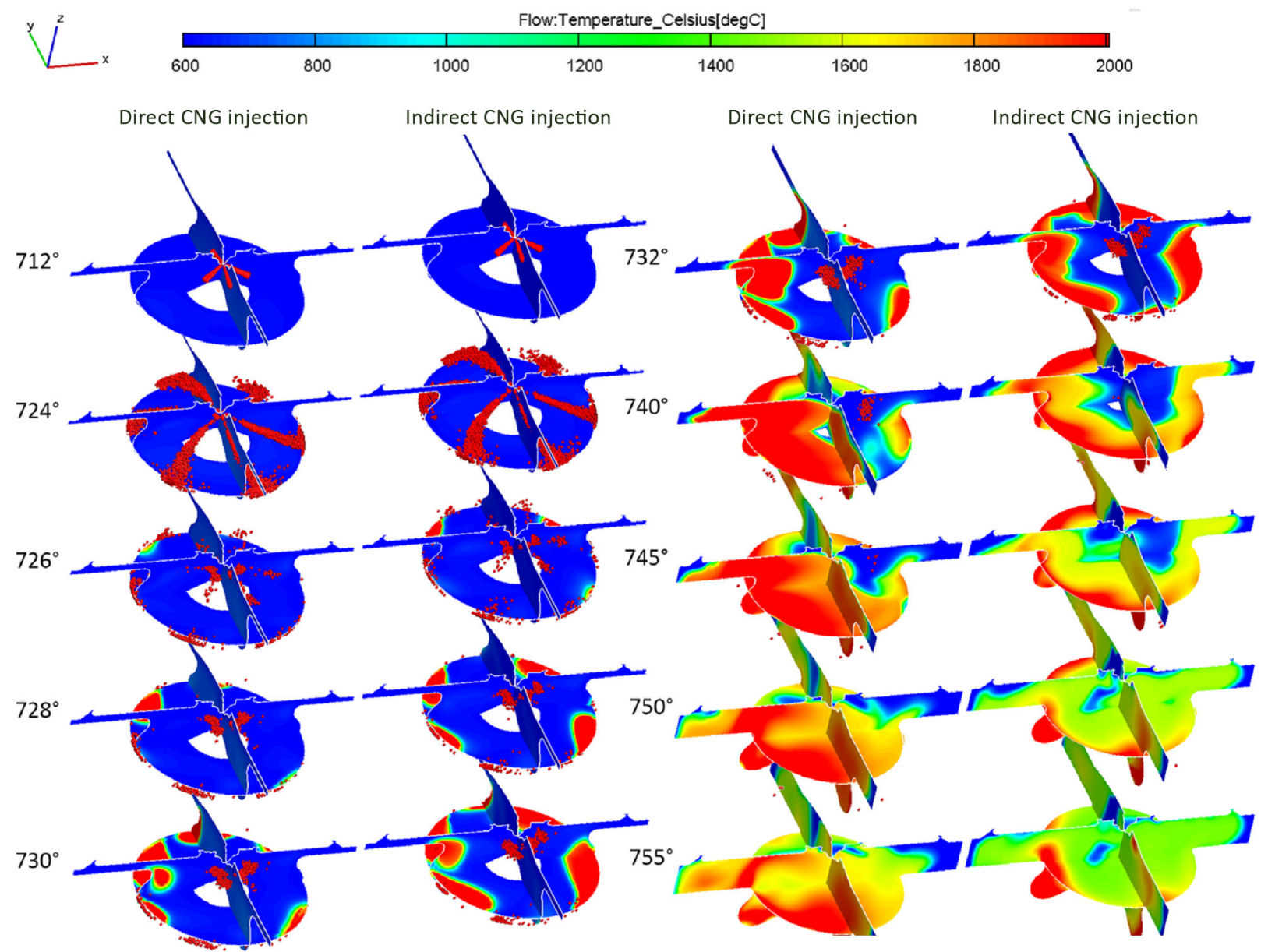

Fig. 6 Temperature distribution and diesel droplets for direct and indirect injection case in different crank angle position.

Figure 7 shows the average temperature in the combustion chamber for different crankshaft rotation angles. Higher temperatures do not mean greater heat losses because the wall temperature is lower than the average.

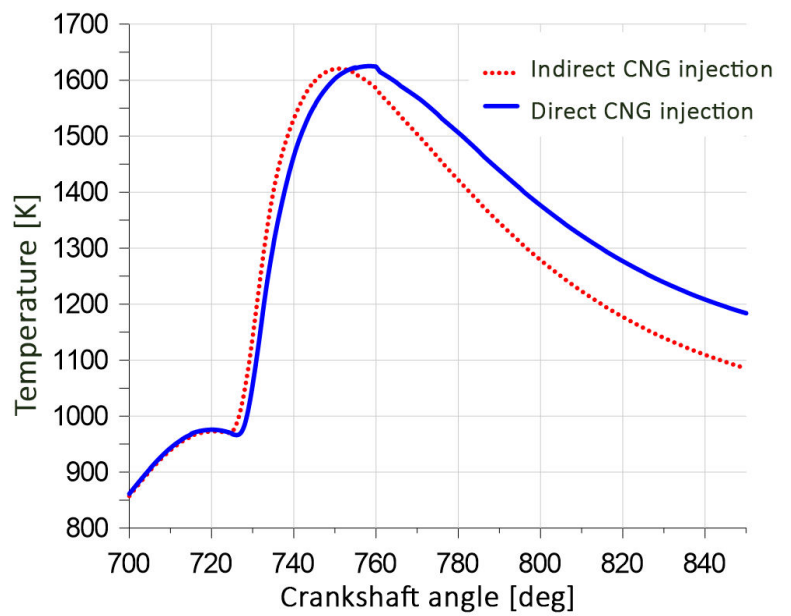

Fig. 7 Average in-cylinder temperature for direct and indirect gas injection.

In spite of similar maximal temperature, the stratification of the mixture results in a polytrophic expansion with the polytrophic exponent more closely related to the adiabatic factor (Fig. 5), thus reducing the heat loss. An early reignition pilot is favourable for faster ignition and combustion process [9]. A dual fuel CNG injection decreases the thermal efficiency slightly when compared to the full diesel injection as shown is study [10][11].

\section{Conclusions}

The full diesel fuel combustion process starts with the auto-ignition of the pre-blended fuel / air mixture, with the kinetic ignition at the beginning. In the majority of the injection, diffusion combustion dominates, leading to the evaporation rate and fuel burning rate equilibrium. Diffusion of the heterogeneous mixture allows to control the combustion rate, respectively extending and increasing the average effective pressure when compared to the combustion of the homogeneous mixture. Long fuel injection reduces the maximum temperature and pressure values, reducing the risk of excessive emissions of harmful nitrogen oxides. Through indirect injection, $\mathrm{CNG}$ produces a homogeneous mixture in the combustion chamber. The later the injection, the less homogeneous the mixture at the time of diesel injection. However, it is important to remember that there is a limitation of direct injection of $\mathrm{CNG}$, as the counter-pressure in the combustion chamber increases. The advantages of heterogeneous 
mixtures are: better thermal efficiency (less heat is lost through the cylinder walls during the combustion and expansion phase) and a higher degree of fuel burnout. Proper direct injection is more efficient than indirect injection in terms of engine economy (higher cycle efficiency) and reduced emissions of harmful substances. Improvements are also occurring intransient states, where direct injection is more reliable as the entire dose is applied to the combustion chamber during the same cycle. In the indirect injection, a part of the injected dose is taken from subsequent cycles. The advantage of CNG injection, by forming a homogeneous mixture, is the reduction soot formation which occurs in poor combustion areas.

\section{References}

1. K. U. Leuven, F. Ingenieurswetenschappen, D. Werktuigkunde, A. T. Mechanica, E. N. Energieconversie, Katholieke Universiteit Leuven Thesis (2008).

2. M. J. Staś, J. Kones, 7, 485-496, (2000).

3. K. Ryu, Energy Convers. Manag., 76, 506-516, (2013).
4. A. Ambrozik, T. Ambrozik, D. Kurczyński, P. Łagowski, Proc. Inst. Veh., 2, no 8, 5-12, (2012).

5. A. I. Ramírez, S. Som, T. P. Rutter, D. E. Longman, and S. K. Aggarwal, Spring Technical Meeting of the Central States Section of the Combustion Institute, 22-24, (2012)

6. Y. Shi and R. D. Reitz, Modelling Diesel CombustionMulti-dimensional CFD modelling of diesel combustion:Overview. (2009).

7. A. Paykani, A. H. Kakaee, P. Rahnama, and R. D. Reitz, Energy, 90, 814-826, (2015).

8. R. G. Papagiannakis and D. T. Hountalas, Appl. Therm. Eng., 23, no. 3, pp. 353-365, (2003).

9. S. Imran, D. R. Emberson, A. Diez, D. S. Wen, R. J. Crookes, and T. Korakianitis, Appl. Therm. Eng., 67, no. 1-2, 354-365, (2014).

10. S. Imran, D. R. Emberson, B. Ihracska, D. S. Wen, R. J. Crookes, and T. Korakianitis, Int. J. Hydrogen Energy, 39, no. 10, pp. 5163-5175, (2014).

11. M. Xu, W. Cheng, Z. Li, H. Zhang, T. An, and Z. Meng, Appl. Energy, 179, 1185-1193, (2016) 